\title{
Effects of regular and irregular temporal patterns of disturbance on biomass accrual and species composition of a subtidal hard-bottom assemblage
}

\author{
Susanne Wollgast $\cdot$ Mark Lenz $\cdot$ Martin Wahl $\cdot$ \\ Markus Molis
}

Received: 19 November 2007 / Revised: 30 April 2008 / Accepted: 5 May 2008 / Published online: 11 June 2008

(C) Springer-Verlag and AWI 2008

\begin{abstract}
Assessing patterns of species distribution and abundance is important to understand the driving processes of, and predict future changes in, biodiversity. To this date, ecological studies have been mainly designed to investigate the effects of the mean magnitude of predictor variables, although ecological factors naturally vary in space and time. In a nine month long field experiment, we tested the effects of different temporal patterns (regular, lowly and highly irregular) in biomass removal (=disturbance event) on the diversity, species composition, and biomass accrual of macrobenthic assemblages grown on $15 \times 15 \mathrm{~cm}^{2}$ PVCpanels. For each pattern of disturbance, disturbance events were timed at three sequences to control for possible confounding effects with recruitment patterns. Disturbance intensity was kept identical among treatments. Assemblages developed in the absence of disturbance for 3 months prior to a 150 -day manipulation period, during which the biomass from $20 \%$ of the panel area was
\end{abstract}

Communicated by H.-D. Franke.

S. Wollgast and M. Molis contributed equally to this work.

S. Wollgast

University Duisburg-Essen, Universitätsstraße 5,

45117 Essen, Germany

M. Lenz $\cdot$ M. Wahl

IFM-GEOMAR, Leibniz Institute of Marine Sciences

at the University of Kiel, Düsternbrooker Weg 20,

24105 Kiel, Germany

M. Molis ( $\square)$

Section Seaweed Biology, Biologische Anstalt Helgoland, Alfred-Wegener-Institute for Polar and Marine Research, Marine Station, Kurpromenade 201, 27498 Helgoland, Germany e-mail: markus.molis@awi.de removed at each of ten disturbance events. Additional undisturbed settlement panels were deployed in the field to assess monthly recruitment rates and species succession over a one year period. Disturbance (i) reduced biomass and total species cover, (ii) changed species composition during the first half of the manipulation period significantly, and (iii) was without effect on species richness and evenness. Irregular disturbance regimes enhanced the abundance of the ascidian Ciona intestinalis, biomass accrual, and total species cover of assemblages relative to the regular disturbance regime, but had either no or only transient effects on diversity and species composition, respectively. Neither the degree of irregularity in disturbance nor the sequence of disturbance events affected any of the response variables significantly. Recruitment of species was strongly seasonal with almost only diatoms recruiting during winter, while recruitment was most intense during summer. Our results suggest that the temporal patterns of predictor variables might be of low explanatory power for the variance of responses in communities with seasonal recruitment patterns that are exposed to a high level of disturbance. Thus the need to include temporal patterns of predictor variables in experimental designs may depend on community dynamics and the characteristics of the process under investigation.

Keywords Community ecology $\cdot$ Hard-bottom . Helgoland $\cdot$ Species richness $\cdot$ Succession

\section{Introduction}

Theoretical and experimental evidence from a variety of habitats suggests that declining diversity can adversely affect the functioning and stability of ecosystems (e.g. 
Loreau 2000; Morin and McGrady-Steed 2004). A change in global diversity may matter to mankind due to an altered provision of ecosystem goods and services (sensu Hooper et al. 2005). Consequently, ecological research needs to assess at various scales which factors affect diversity, to better understand the causes and consequences of the presently observed loss of species (Hughes et al. 1997).

Disturbance is perhaps the best studied factor affecting local patterns of species diversity in both terrestrial and aquatic systems (Menge and Sutherland 1987). Disturbances are defined as stochastic and discrete events, causing partial or total destruction of biomass (Grime 1977). Common to the different kinds of disturbance is the release of limiting resources, e.g. substrate, which alters niche opportunities (Shea et al. 2004). Previous studies on disturbance-diversity relationships did not allow for drawing general conclusions on the effects of disturbance. For instance, from meta-analysis of studies testing the 'Intermediate Disturbance Hypothesis (IDH)', Mackey and Currie (2001) concluded that diversity-disturbance relationships did not peak as consistently as predicted by the IDH. This suggests that factors other than disturbance per se control diversity patterns. For instance, the interactive effects of productivity and disturbance were hypothesized to increase the predictability of disturbance effects on species diversity (Kondoh 2001), with limited support from field experiments (Jara et al. 2006; Svensson et al. 2007).

Under natural conditions, biological responses are determined by a variable environment. For instance, predator attacks are not evenly distributed in time and space, resulting in variable consumer-resource interactions (Sommer 2000). Despite the wide acceptance of this notion, the majority of experiments in ecology assessed the effects of different mean magnitudes of factors on ecological processes. Designing experiments that include the effects of temporal or spatial irregularity in disturbance regimes may produce more realistic data (Benedetti-Cecchi 2003), which could also improve the predictability of disturbance-diversity relationships. Some studies that used different temporal patterns of predictor variables, manipulated the frequency of the predictor variable, e.g. predation (Navarrete 1996), thereby confounding temporal irregularity and intensity of predation. Only a few studies, all but one (Sugden et al. 2007) conducted in the Mediterranean, rigorously tested the effects of the variation of disturbance events on community responses (BenedettiCecchi et al. 2005, 2006; Bertocci et al. 2005, 2007). However, these studies focused on the interactive effects of mean intensity and temporal variability of e.g. disturbance, and did not assess the interactive effects of irregular disturbance patterns and the sequence of disturbance events. Testing the effects of the sequence of disturbance events is necessary to tease apart the effects of irregularity of disturbance from those of seasonal recruitment periods of organisms (Bertocci et al. 2005). If disturbance events coincide with the period of recruitment of species having a discontinuous release of propagules, community responses may be due to the specific sequence of disturbance events, rather than to irregular disturbance patterns (BenedettiCecchi 2003).

Experiments testing the effects of variability of those environmental factors, such as climate, that currently undergo a rapid change are of particular interest. For instance, altered disturbance regimes from a climate change induced modification in the frequency and intensity of storms are expected to have striking effects on the ecology of coastal systems (Kjerfve et al. 1994). In the German Bight, storm frequency and intensity increased over the last decades (Danard et al. 2004) and may affect benthic community structure, e.g. due to the overturning of boulders in subtidal habitats or by battering of drift wood in intertidal habitats. Using a multi-factorial field experiment, we assessed the effects of (1) a physical disturbance, (2) the temporal irregularity in a disturbance regime while keeping disturbance intensity constant, and (3) the sequence of disturbance events on biomass accrual, diversity, and species composition of subtidal macrobenthic assemblages at the Island of Helgoland, North Sea.

\section{Material and methods}

Study site

One observational and one manipulative field experiment were conducted at "Nebelhorn" $\left(54^{\circ} 10^{\prime} 57^{\prime \prime} \mathrm{N}, 7^{\circ} 53^{\prime} 7^{\prime \prime} \mathrm{E}\right)$, a wave sheltered site in the outer harbour of the Island of Helgoland, Germany. There, large stones (bunker debris) are scattered over soft sediments in $7.5 \mathrm{~m}$ water depth and a concrete jetty frames the study site at two sides. These artificial hard substrata are covered by typical members of subtidal communities, including algae, barnacles, amphipods, ascidians, and bryozoans, which were also found elsewhere on the rocky shores of Helgoland (de Kluijver 1991). Species recruitment around Helgoland follows a strong seasonal pattern that was observed at different sites (including the study site) and in different years (Anger 1977; Harms and Anger 1983). Whilst a few species of algae start recruitment between February and May, the majority of species colonize substrata in a firm schedule of species-specific settlement peaks between June and September. As a result, space becomes a limiting resource by the end of June and maximum diversity is reached by mid August, when assemblages are fully developed (Anger 1977). 
Experimental design and set-up

\section{Variability experiment}

A manipulative factorial experiment was designed to test for the effects of temporal irregularity of a physical, nonselective disturbance regime (four levels, fixed: control, regular, lowly, and highly irregular) on biomass accrual, diversity, and species composition of epibenthic communities. Disturbance events were scheduled at three different sequences, nested in a low and a high level of temporal irregularity, resulting in a total of eight treatment combinations (Fig. 1).

The experiment was conducted between February 14 and October 24, 2005. Two larger buoys $(\varnothing 50 \mathrm{~cm})$, at a distance of $20 \mathrm{~m}$, were connected by a line at the water surface, and each buoy was attached to one ground weight. This mooring was ca. $70 \mathrm{~m}$ away from the concrete jetties framing the study site. Eight smaller buoys $(\varnothing$ $15 \mathrm{~cm}$ ) were fixed to the surface line to keep it floating. Eight grey PVC rings $(60 \mathrm{~cm} \varnothing, 25 \mathrm{~cm}$ height, $3 \mathrm{~mm}$ thick) that served as experimental blocks were fixed to the surface line. The distance between adjacent rings was $\geq 2 \mathrm{~m}$. Rings were allowed to rotate around their centre axis. Ten grey PVC settlement-panels (experimental units $=$ EUs) were fixed at a distance of $5 \mathrm{~cm}$ between adjacent panels perpendicular to the sea floor to the inside of each ring (total of $80 \mathrm{EUs})$. Concrete weights $(3 \mathrm{~kg})$ were fixed to rings without reaching the sea floor, to ensure that rings and therefore EUs were suspended at $0.5 \mathrm{~m}$ water depth with reference to panel centre. Neither benthic nor pelagic predators were observed on the set-up.
Furthermore, missing bit marks indicate that our set-up generated a consumer-free space, minimising confounding effects by consumer activity to disturbance treatments. Settlement panels of $15 \times 15 \mathrm{~cm}^{2}$ ( $3 \mathrm{~mm}$ thick) were roughened (sand paper grading 60) and randomly allocated to a disturbance treatment. Since the number of EUs per block, i.e. 10, exceeded the number of treatment combinations, i.e. 8, two within-block replicates, both of different treatment combination, were added to each block (Fig. 2).

\section{Succession experiment}

An observational study was designed to assess temporal patterns in recruitment and succession of species on settlement panels over an 11-month period. On May 27, 2005, 16 PVC panels with properties identical to those used in the variability experiment were fixed with ropes to the surface line of the above described mooring. PVC panels were positioned at $50-\mathrm{cm}$ water depth and a distance of $60 \mathrm{~cm}$ to each other as well as to the rings of the variability experiment. Half of the panels (recruitment panels, $n=8$ ) were randomly selected to assess species recruitment by estimating percent cover of each sessile species encountered on the panels (see "sampling" for details). After sampling, all biota were removed and clean panels returned within $24 \mathrm{~h}$ to the set-up. This procedure was monthly repeated until the last sampling on April 25, 2006. The second half of the panels (succession panels, $n=8$ ) was used to follow species succession for 11 months. Succession panels were always sampled together with and in the same way as recruitment panels. However, biota were not
Fig. 1 Variability experiment. Temporal patterns of disturbance events for all eight treatment combinations. Single boxes represent 5-day intervals. Open boxes indicate among disturbance intervals, while filled boxes mark intervals when a disturbance event was applied on the first day of this interval. Different levels of disturbance variation are colour-coded: black regular, dark grey lowly irregular, and light grey highly irregular. Patterns of box fillings indicate different sequences ( $a$ full, $b$ brick, and $c$ chess board) of disturbance events. Numbers at the start of lines code different treatment combinations.

Sampling dates are arrowed
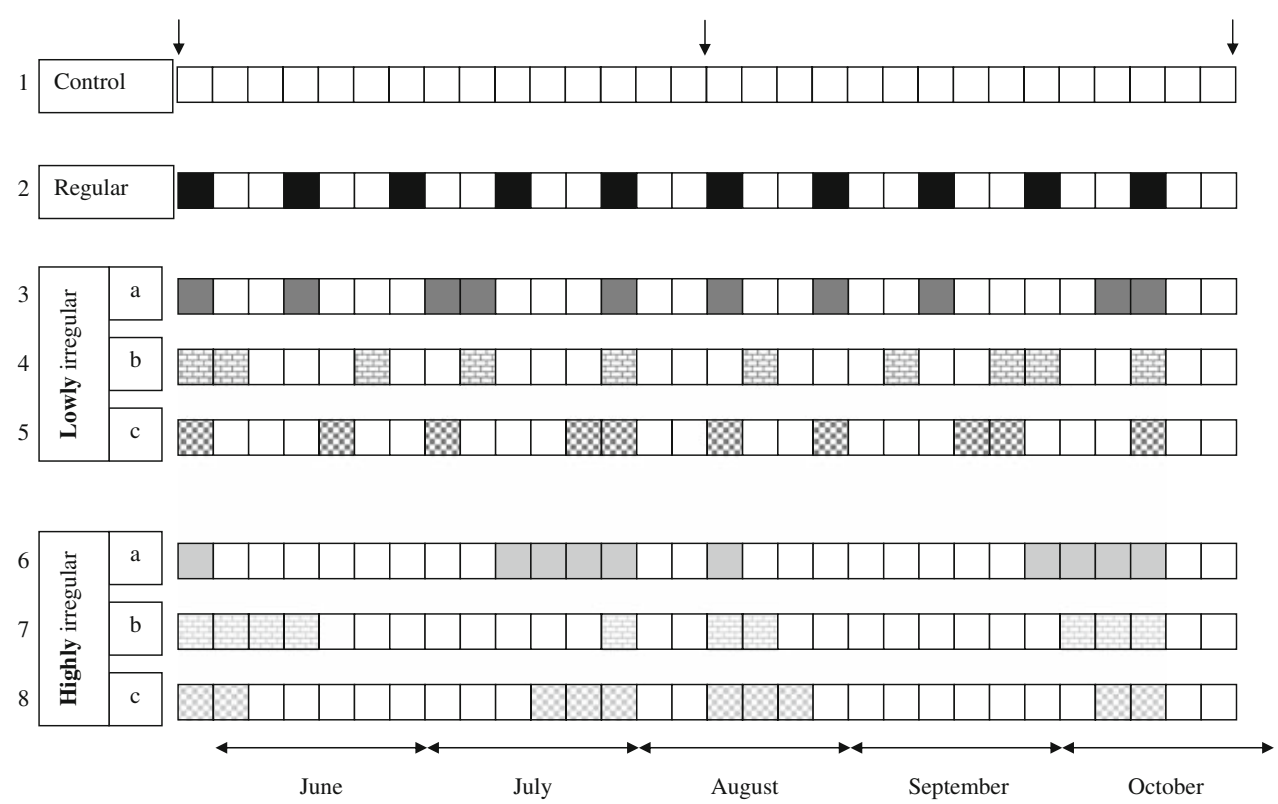


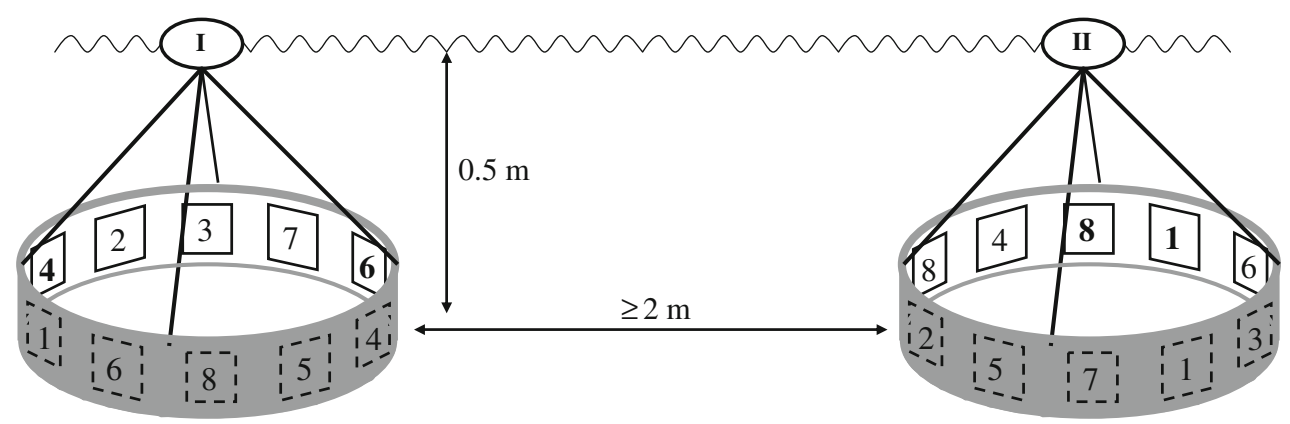

Fig. 2 Schematic illustration of two (roman numbers in buoys) adjacent rings (=blocks) from part of the set up. Squares and numbers inside squares indicate the position of settlement panels within rings and allocated treatment levels (total number of treatment

removed and panels with attached assemblages were returned to the set-up.

\section{Treatments}

All experimental units were disturbed for the first time on 27 May 2005, after they had been incubated at the study site without manipulation for 13 weeks to allow for the establishment of early successional epibenthic assemblages (Fig. 3, May). During the 150-day manipulation period, assemblages on all panels (except controls) were disturbed 10 times; therefore, they experienced the identical disturbance intensity. At a single disturbance event, we removed the entire biomass from two randomly selected, non-overlapping circular spots, representing together $20 \%$ of the area of each settlement panel. As the selection of disturbance areas was at random, the same area could be disturbed at successive disturbance events. Assemblages were disturbed every fifth day or a multiple thereof (Fig. 1). In the "regular" treatment, communities were disturbed every 15 days, i.e. at regular intervals. Irregularity of intervals between disturbance events was defined as the standard deviation of among disturbance intervals from the mean interval length of 15 days (=no variability). By accordingly timing the disturbance events, a lowly irregular $(\mathrm{SD}=5.77)$ and a highly irregular $(\mathrm{SD}=16.33)$ treatment were applied (Fig. 1). To reduce the risk of confounding the effects of irregularity of disturbance with recovery time (Bertocci et al. 2005), the period between the last disturbance event and the end of the experiment was kept identical to 15 days in all disturbance treatments. A further assumption underlying our experiment is that the effects of removing biomass, and by this opening space for new settlers, should depend on temporal patterns in larval and propagule settlement. To assess possible interactions between the sequence of disturbance events and the degree of irregularity of disturbance, three different sequences of disturbance events were applied for both, the low and high irregularity treatment, combinations $=8$ ), respectively. Bold font indicates within block replicates. Distances are arrowed. Note: drawing not to scale. For clarity, the surface line and concrete weights are not shown

without changing the level of irregularity nor intensity of disturbance (Fig. 1).

\section{Sampling}

For sampling, panels were removed from the set-up, transferred in shaded containers within 15 min to the laboratory of the Biologische Anstalt Helgoland, maintained in large flow-through containers, and returned within $24 \mathrm{~h}$ to the set-up. In the laboratory, percent cover of all sessile species (>1 mm) encountered on the panels was estimated nondestructively by the same person prior to (27 May 2005), in the middle (10 August 2005), and at the end of the manipulation period (October 24, 2005). Mobile species were not recorded. A $1 \mathrm{~cm}$ wide band along panel margins was ignored to avoid edge effects, leaving $169 \mathrm{~cm}^{2}$ of sampling area per EU. Diatoms and green filamentous algae were recorded as two group taxa, because non-destructive sampling prevented unambiguous species identification. All other colonizers were identified to the lowest possible taxonomic level, usually to species level. Percent cover of macroscopic species in the area sampled was estimated by the naked eye and, using a stereo microscope $(12 \times$ magnification) for those species that were not detectable macroscopically, from six randomly chosen $2 \times 2 \mathrm{~cm}^{2}$ sized subsamples. Due to the multi-layered structure of the fouling assemblages, total percent cover could exceed $100 \%$. In the middle and at the end of the manipulation period, biomass was non-destructively assessed as wet mass after resting panels for 1 min vertically to allow drainage of excess water, weighing communities still attached to panels to the nearest $0.1 \mathrm{~g}$, and subtracting panel mass. At the end of the experiment, dry mass was measured for each EU by removing all organisms from the sampling area, drying them at $60^{\circ} \mathrm{C}$ to constant weight, and weighing to the nearest $0.001 \mathrm{~g}$. As diversity variables, species richness was recorded, while Pielou's evenness was calculated from abundance data. 
Fig. 3 Mean (+SD) total cover and average percent cover of taxa of communities prior to manipulations (May), in the middle (August), and at the end (October) of the manipulation period. Controls sharing a letter were not significantly different. Solid horizontal lines group contrasts among assemblages after exposure to different disturbance regimes in the middle and at the end of the 150-day manipulation period

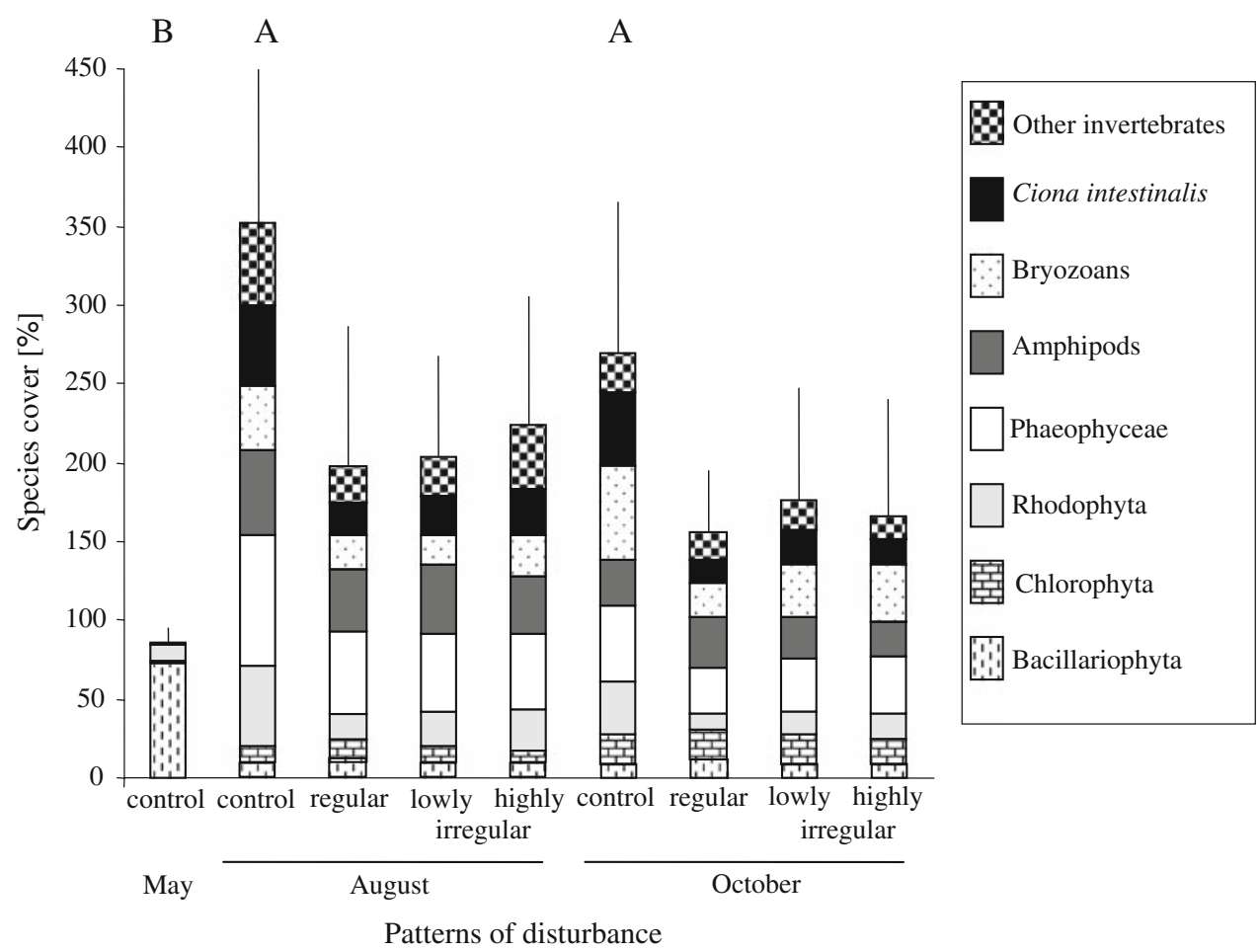

\section{Statistical analysis}

Data were tested for homogeneity of variances prior to the analysis and log-transformed where appropriate to meet the assumptions (Cochran's test). Diversity and biomass data from undisturbed (control) assemblages were compared between the three sampling events using a 1-factorial ANOVA and Tukey's HSD post hoc test. We tested for the effects of the factors "disturbance", "irregularity of disturbance", and "sequence of disturbance events" in the middle and at the end of the 150-day manipulation period with a multi-staged ANOVA. First, we obtained the variation between replicates on the block level, i.e. the error term, from a mixed model two-factorial ANOVA, including the replicates of treatments in each block (fixed, two levels) and blocks (random, eight levels) as factors. Second, we used a three-factorial nested ANOVA, with the "sequence of disturbance events" (random, three levels), which was nested within "irregularity of disturbance" (fixed, four levels), and crossed with "block" (random, eight levels). When the "block" $\times$ "irregularity of disturbance" interaction was non-significant at $\alpha \geq 0.25$, the term was eliminated from the model and we tested for effects of "disturbance", "irregularity of disturbance", and "sequence of disturbance events".

Treatment effects on the composition of fouling communities were assessed with ANOSIM (Primer 5.0), based on multidimensional scaling of the Bray-Curtis similarity index. The SIMPER routine was used for exploration of the relative contribution of species to observed differences in community composition.

\section{Results}

Variability experiment

\section{Community composition}

In total, 31 taxa were encountered on the settlement panels (Table 1). In May 2005, prior to manipulations, diatoms dominated the assemblage (Fig. 3), but five species of macroalgae and two invertebrate species were also present. In August, tube-dwelling amphipods, mainly Jassa falcata, were the most abundant taxon on undisturbed assemblages. There were 1.5 times more invertebrates (13) than macroalgae taxa (9) on undisturbed plots. At the end of the experiment in October, a total of 29 taxa were encountered on the settlement panels. Besides diatoms, we identified 16 species of invertebrates and 12 macroalgae. The large solitary sea squirt Ciona intestinalis was on average the most abundant species, occasionally completely covering control panels; followed by the bryozoan Scupocellaria scruposa and the amphipod $J$.falcata. The most abundant seaweeds were the red alga Ceramium virgatum and the green alga Ulva lactuca. Species composition in August was significantly different among differently disturbed assemblages (ANOSIM: $R=0.10, P=0.001)$. The species composition of 
Table 1 Dots indicate times when species were encountered during succession experiment (black) and disturbance experiment (white)

\begin{tabular}{|c|c|c|c|c|c|c|c|c|c|c|c|}
\hline & \multicolumn{7}{|l|}{2005} & \multicolumn{4}{|c|}{2006} \\
\hline & May & Jun & Jul & Aug & Sep & Oct & Nov & Jan & Feb & Mar & Apr \\
\hline \multicolumn{12}{|l|}{ Algae } \\
\hline Bacillariophyta & $\bullet$ & $\bullet$ & $\bullet$ & $\bullet$ & $\bullet$ & $\bullet$ & $\bullet$ & $\bullet$ & $\bullet$ & $\bullet$ & $\bullet$ \\
\hline \multicolumn{12}{|l|}{ Rhodophyta } \\
\hline Ceramium virgatum & $\bullet$ & • & $\bullet$ & $\bullet$ & - & $\bullet$ & - & $\bullet$ & $\bullet$ & 0 & ○ \\
\hline Polysiphonia stricta & & & & $\bullet$ & - & $\bullet$ & - & $\bullet$ & • & ○ & ○ \\
\hline P. elongata & & $\bullet$ & $\bullet$ & $\bullet$ & $\bullet$ & $\bullet$ & $\bullet$ & $\bullet$ & $\bullet$ & $\bullet$ & $\bullet$ \\
\hline Callithamnion corymbosum & & & & & & $\bullet$ & & $\bullet$ & $\bullet$ & & ○ \\
\hline Plocamium cartilagineum & & & & & & $\bullet$ & - & - & - & - & - \\
\hline Lomentaria clavellosa & & & & & & $\bullet$ & & & & & \\
\hline \multicolumn{12}{|l|}{ Phaeophyceae } \\
\hline Desmarestia aculeata & ○ & & $\bullet$ & $\bullet$ & $\bullet$ & $\bullet$ & & & & & \\
\hline Laminaria digitata & $\bullet$ & - & $\bullet$ & $\bullet$ & & $\bullet$ & - & & & ○ & - \\
\hline Chorda filum & & & $\bullet$ & $\bullet$ & $\bullet$ & $\bullet$ & & & & & $\bullet$ \\
\hline Scytosiphonaceae & & $\bullet$ & $\bullet$ & $\bullet$ & $\bullet$ & $\bullet$ & $\bullet$ & $\bullet$ & & $\bullet$ & \\
\hline \multicolumn{12}{|l|}{ Cholophyta } \\
\hline Ulva lactuca & O & - & $\bullet$ & $\bullet$ & $\bullet$ & $\bullet$ & $\bullet$ & $\bullet$ & • & $\bullet$ & $\bullet$ \\
\hline Filamentous green algae & $\bullet$ & & $\bullet$ & $\bullet$ & & $\bullet \circ$ & $\bullet$ & $\bullet$ & $\bullet$ & $\bullet$ & $\bullet$ \\
\hline Bryopsis lyngbyei & & & & & & & $\bullet$ & & $\bullet$ & $\bullet$ & $\bullet$ \\
\hline \multicolumn{12}{|l|}{ Invertebrates } \\
\hline \multicolumn{12}{|l|}{ Ascidians } \\
\hline Ciona intestinalis & & $\bullet$ & $\bullet$ & $\bullet$ & $\bullet$ & $\bullet$ & $\bullet$ & $\bullet$ & $\bullet$ & $\bullet$ & $\bullet$ \\
\hline Ascidiella aspersa & & & & $\bullet$ & $\bullet$ & $\bullet$ & $\bullet$ & & & & \\
\hline Botryllus schlosseri & & & & $\bullet$ & & & & & & & \\
\hline Botrylloides leachii & & & & $\bullet$ & $\bullet$ & $\bullet$ & & & & & \\
\hline Sidnyum turbinatum & & & & $\bullet$ & & & & & & & \\
\hline Diplosoma listrium & & & & $\bullet$ & - & $\bullet$ & ○ & - & $\bullet$ & ○ & $\bullet$ \\
\hline Didemnum macrulosum & & & & $\bullet$ & $\bullet$ & ○ & & $\bullet$ & • & & \\
\hline Molgula spec. & & & & & & $\bullet$ & & & & & \\
\hline \multicolumn{12}{|l|}{ Crustaceans } \\
\hline Jassa falcata & $\bigcirc$ & $\bullet$ & $\bullet$ & $\bullet$ & $\bullet$ & $\bullet$ & $\bullet$ & $\bullet$ & $\bullet$ & $\bullet$ & \\
\hline Balanus crenatus & & $\bullet$ & $\bullet$ & $\bullet$ & - & $\bullet$ & $\bullet$ & $\bullet$ & $\bullet$ & $\bullet$ & $\bullet$ \\
\hline Elminius modestus & & $\bullet$ & & $\bullet$ & & $\bullet \circ$ & $\bullet$ & $\bullet$ & $\bullet$ & $\bullet$ & $\bullet$ \\
\hline Verruca stroemia & & & & $\bullet$ & $\bullet$ & $\bullet$ & & $\bullet$ & $\bullet$ & - & $\bullet$ \\
\hline \multicolumn{12}{|l|}{ Bryozoans } \\
\hline Electra pilosa & $\bigcirc$ & & $\bullet$ & $\bullet$ & $\bullet$ & $\bullet$ & & & & & $\bullet$ \\
\hline Scupocellaria scruposa & & & $\bullet$ & $\bullet$ & $\bullet$ & $\bullet$ & $\bullet$ & $\bullet$ & $\bullet$ & $\bullet$ & $\bullet$ \\
\hline Cryptosula pallasiana & & & & $\bullet$ & $\bullet$ & $\bullet$ & $\bullet$ & $\bullet$ & $\bullet$ & & $\bullet$ \\
\hline \multicolumn{12}{|l|}{ Molluscs } \\
\hline Mytilus edulis & & $\bullet$ & $\bullet$ & $\bullet$ & $\bullet$ & $\bullet$ & $\bullet$ & $\bullet$ & $\bullet$ & $\bullet$ & $\bullet$ \\
\hline Ostrea spec. & & & & $\bullet$ & & $\bigcirc$ & & & & & \\
\hline \multicolumn{12}{|l|}{ Polychaetes } \\
\hline Pomatoceros triqueter & & & & & & $\bullet$ & & & & & \\
\hline \multicolumn{12}{|l|}{ Hydroids } \\
\hline Obelia geniculata & & $\bullet$ & $\bullet$ & $\bullet$ & - & $\bullet$ & $\bullet$ & $\bullet$ & & & • \\
\hline \multicolumn{12}{|l|}{ Porifera } \\
\hline Sycon coronatum & & & & & & & & $\bullet$ & & & \\
\hline
\end{tabular}

Filamentous green algae group a conglomerate of different species of green algae, including the genera Monostroma, Ulva, and Chaetomorpha, for which unambiguous identification in the field was impossible 
Table 2 ANOVA-results for community biomass [wet mass in August (75 days) and dry mass in October (150 days)] and species abundances

\begin{tabular}{|c|c|c|c|c|c|c|c|c|c|c|c|c|c|}
\hline \multirow[t]{3}{*}{ Source } & \multirow[t]{3}{*}{$d f$} & \multicolumn{4}{|c|}{ Biomass } & \multicolumn{4}{|c|}{ Total species cover } & \multicolumn{4}{|c|}{ Ciona intestinalis cover } \\
\hline & & \multicolumn{2}{|c|}{75 days } & \multicolumn{2}{|c|}{150 days } & \multicolumn{2}{|c|}{75 days } & \multicolumn{2}{|c|}{150 days } & \multicolumn{2}{|c|}{75 days } & \multicolumn{2}{|c|}{150 days } \\
\hline & & $F$ & $P$ & $F$ & $P$ & $F$ & $P$ & $F$ & $P$ & $F$ & $P$ & $F$ & $P$ \\
\hline Disturbance (D) & 1 & 34.32 & 0.001 & 28.66 & 0.001 & 20.93 & 0.003 & 7.32 & $\mathbf{0 . 0 3 0}$ & 0.28 & 0.941 & 3.49 & 0.104 \\
\hline Irregularity (I) & 1 & 32.61 & 0.001 & 26.61 & 0.001 & 20.62 & 0.003 & 7.84 & 0.035 & 9.01 & $\mathbf{0 . 0 2 0}$ & 3.34 & 0.110 \\
\hline Degree of irregularity (DI) & 1 & 2.83 & 0.136 & 1.03 & 0.345 & 0.74 & 0.418 & 0.18 & 0.685 & 0.40 & 0.547 & 0.92 & 0.368 \\
\hline Sequence (irregularity) SQ (I) & 1 & 1.00 & 0.422 & 0.11 & 0.977 & 1.41 & 0.255 & 0.48 & 0.747 & 2.67 & 0.053 & 0.65 & 0.629 \\
\hline Block (B) & 7 & 2.85 & 0.023 & 3.11 & 0.015 & 2.95 & 0.019 & 0.64 & 0.716 & 3.40 & 0.009 & 1.67 & 0.157 \\
\hline $\mathrm{B} \times \mathrm{D}$ & 7 & 1.55 & 0.192 & 0.96 & 0.475 & 5.31 & 0.001 & 1.56 & 0.183 & 0.80 & 0.594 & 0.04 & 1.000 \\
\hline $\mathrm{B} \times \mathrm{I}$ & 7 & 0.47 & 0.849 & 0.24 & 0.970 & 2.91 & 0.020 & 0.39 & 0.898 & 0.50 & 0.827 & 0.46 & 0.855 \\
\hline $\mathrm{B} \times \mathrm{DI}$ & 7 & 0.46 & 0.852 & 0.86 & 0.549 & 2.15 & 0.071 & 1.06 & 0.415 & 1.76 & 0.135 & 1.53 & 0.197 \\
\hline $\mathrm{B} \times \mathrm{SQ}(\mathrm{I})$ & 28 & 0.61 & 0.875 & 0.63 & 0.860 & 0.73 & 0.771 & 0.69 & 0.807 & 0.91 & 0.597 & 0.84 & 0.666 \\
\hline Residual & 16 & & & & & & & & & & & & \\
\hline
\end{tabular}

Total species cover and $C$. intestinalis cover data were arcsine-transformed prior to the analysis. Significant results in bold font $d f$ degrees of freedom

undisturbed control assemblages was significantly different from that of assemblages exposed (i) to the regular as well as (ii) to the lowly irregular disturbance regime. The species contributing $>50 \%$ to these differences were, in declining order of significance, the brown seaweed Desmarestia aculeata, the ascidian C. intestinalis, the red alga C. virgatum, the amphipod J. falcata, and the mussel Mytilus edulis. Each species was consistently more abundant in undisturbed assemblages than in those under regular and lowly irregular disturbance regimes. In October, the global analysis showed no significant differences among undisturbed communities and those exposed to any of the disturbance regimes (one-way ANOSIM: $R=0.06, P=0.055$ ).

\section{Species abundance and community biomass}

Total cover of undisturbed assemblages changed significantly during the course of the experiment (ANOVA: $\left.F_{2,26}=14.31, P<0.001\right)$. Total cover on undisturbed panels increased by a significant four times between May and August and showed a non-significant $21 \%$ decrease until October (Fig. 3). Total cover was a significant 42 and 38\% lower on disturbed than on undisturbed panels in August and October, respectively (Table 2; Fig. 3). Furthermore, total species cover was a significant 8 and $10 \%$ lower on regularly than on irregularly disturbed panels in August and October, respectively. Neither the degree of irregularity in disturbance (low vs. high) nor the sequence of disturbance events affected total species cover significantly. Significant interactive block $\times$ disturbance and block $\mathrm{x}$ irregularity effects indicate that the main effects of disturbance and irregularity of disturbance were dependent on the position of experimental units at the study site. Disturbance itself had a strong effect on biomass accrual (Table 2). The biomass of disturbed assemblages was on average a significant 1.6 and 3.4 times lower than the biomass of undisturbed assemblages in August (wet mass) and October (dry mass), respectively (Fig. 4a). Moreover, biomass differed significantly among the disturbance regimes (Table 2). Biomass accrual in irregularly disturbed assemblages was on average 10 and $19 \%$ higher than in regularly disturbed assemblages in August and October, respectively (Fig. 4a). Neither the degree of irregularity (low vs. high) nor the sequence of disturbance events significantly affected biomass accrual. The significant block effect at both sampling times indicates that biomass accrual was different across the study site.

Because $C$. intestinalis contributed most to changes in species composition among disturbance treatments, we analysed disturbance effects on the abundance of this ascidian species separately. Disturbance was without effect on C. intestinalis abundance at both sampling times. Yet, C. intestinalis cover was significantly higher on irregularly disturbed than on regularly disturbed panels after 75 days of manipulation. This effect disappeared during the second half of the manipulation period (Table 2; Fig. 3). Timing of disturbance was without significant effect on $C$. intestinalis abundance (Table 2). After 75 days of manipulation, the abundance of $C$. intestinalis was significantly different across the study site.

\section{Diversity}

Evenness of the undisturbed assemblages increased during the course of the experiment and was three times lower in May (evenness: $0.29 \pm 0.13)$ than in August $(0.85 \pm 0.07)$ and October $(0.86 \pm 0.02)$. Similarly, species richness increased significantly with the successional age of undisturbed assemblages (ANOVA: $F_{2,23}=69.45, P<0.001$ ). 

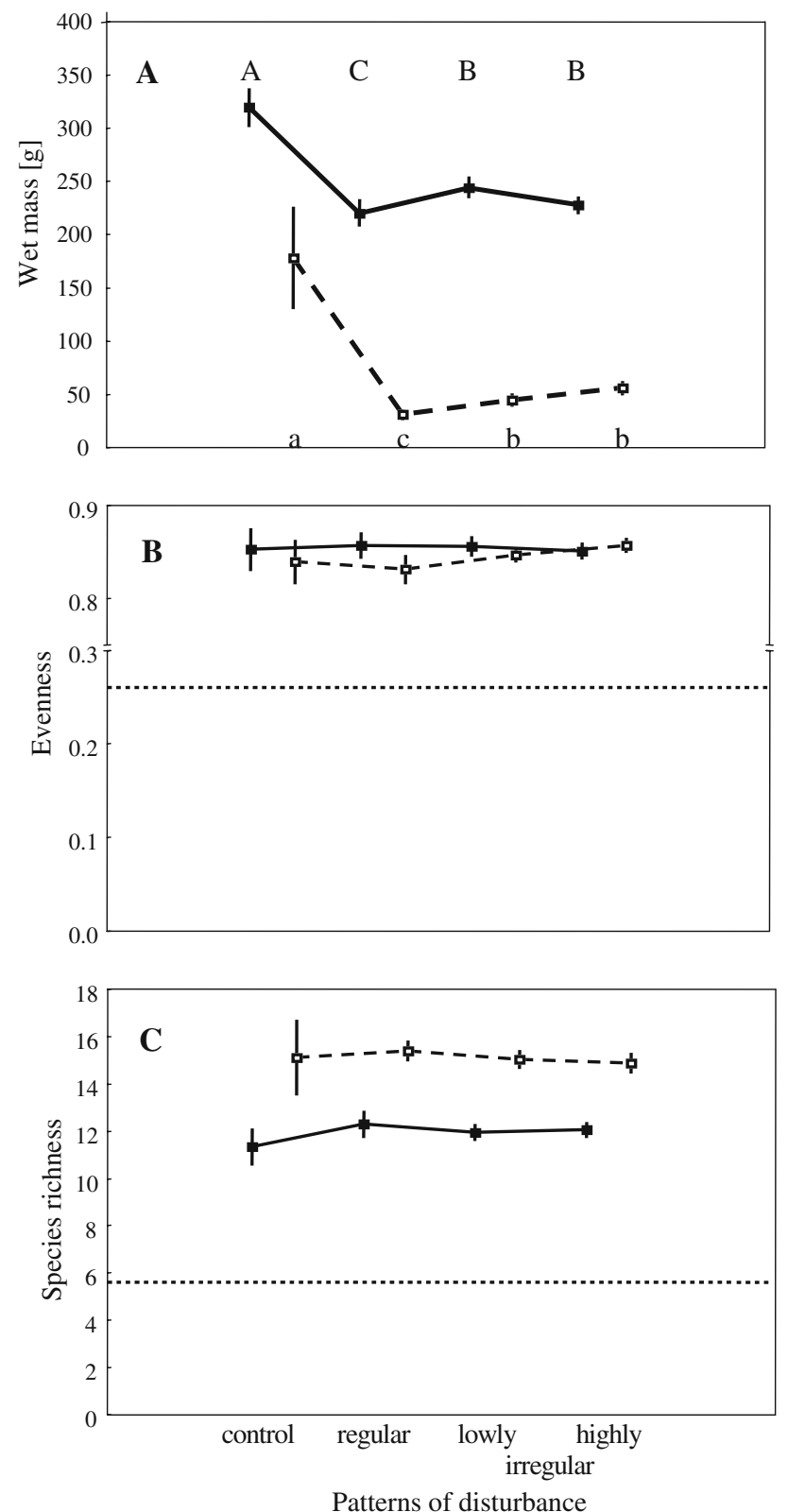

Fig. 4 Mean (+SD) wet mass (a), evenness (b), and species richness (c) of assemblages under different disturbance regimes in the middle (black squares) and at the end (white squares) of the 150-day manipulation period. Stippled horizontal line indicates mean evenness and species richness prior to manipulations. Since the factor "timing of disturbance events" was not significant (at $\alpha>0.25$ ), we pooled the data. Treatments sharing a capital or small letter were not significantly different in the middle and at the end of the manipulation period, respectively. Letters were omitted for non-significant response variables. Note discontinuous ordinate in $4 \mathrm{~B}$

Early successional assemblages (May) had on average two to three times less species $(5.33 \pm 1.70)$ than assemblages in August $(11.33 \pm 2.36)$ and October $(16.63 \pm 1.32)$. After 75 and 150 days, no significant effect of any disturbance treatment was detected on any measure of diversity (Table 3; Fig. 4b, c). However, a significant interaction between "disturbance" and "block" (Table 3) indicates that disturbance effects on evenness were heterogeneous across the study site.

\section{Succession experiment}

\section{Recruitment panels}

Species recruitment at the study site showed a strong seasonal pattern (Fig. 5a). During most of the year, i.e. November-June, almost only diatoms recruited. In contrast, species recruitment was strongest from July to October, with maximum number of recruiting species in August. The ascidian C. intestinalis was only observed in August on recruitment panels, although its abundance on succession panels was much higher in August, suggesting that recruitment of $C$. intestinalis started in July, but recruits were too small to be identified on July recruitment panels. Thus, recruitment panels may reflect patterns lagging actual recruitment by 1 month so that the main recruitment period at the study site may last from June to October.

\section{Succession panels}

A total of 34 species was encountered on succession panels (Table 1). The average number of species increased almost monotonically by a significant fivefold between May 2005 and April 2006 (ANOVA: $F_{9,36}=13.16, P<0.01$ ). Species richness was non-significantly different among assemblages until September, but in October, it was significantly higher than in June and July. Interestingly, the number of species did not change significantly after October until the end of the study. A very similar pattern was detected for the species composition of the assemblages, which changed significantly during the study period (ANOSIM: $R=0.889, P=0.001$ ). However, this difference was only present between younger (until September 2005) and older (from October 2005 to April 2006) assemblages, indicating that assemblages had a persistent species structure over the winter. The ascidian C. intestinalis contributed most (on average almost $30 \%$ ) to the observed differences in assemblage structure. Finally, total species cover also changed significantly during the study period (ANOVA: $F_{9,36}=10.54, P<0.01$, Fig. $5 b$ ), and was at least two times higher in April 2006 than at any other sampling date. Furthermore, total species cover was at least a significant $30 \%$ lower in June and July than during the remaining time of the experiment (Fig. 5b).

\section{Discussion}

Disturbance treatments did not affect the diversity of the macrobenthic assemblages at any time during the experi- 
Table 3 ANOVA-results for diversity measures in August (75 days) and October (150 days)

\begin{tabular}{|c|c|c|c|c|c|c|c|c|c|}
\hline \multirow[t]{3}{*}{ Source } & \multirow[t]{3}{*}{$d f$} & \multicolumn{4}{|c|}{ Evenness } & \multicolumn{4}{|c|}{ Species richness } \\
\hline & & \multicolumn{2}{|c|}{75 days } & \multicolumn{2}{|c|}{150 days } & \multicolumn{2}{|c|}{75 days } & \multicolumn{2}{|c|}{150 days } \\
\hline & & $F$ & $P$ & $F$ & $P$ & $F$ & $P$ & $F$ & $P$ \\
\hline Disturbance D & 1 & 0.06 & 0.821 & 1.27 & 0.297 & 1.41 & 0.274 & 0.11 & 0.746 \\
\hline Irregularity (I) & 1 & 0.02 & 0.896 & 2.05 & 0.195 & 1.25 & 0.301 & 0.10 & 0.765 \\
\hline Degree of irregularity (DI) & 1 & 0.05 & 0.834 & 0.00 & 0.975 & 0.58 & 0.472 & 0.01 & 0.921 \\
\hline Sequence (irregularity) $\mathrm{SQ}(\mathrm{I})$ & 2 & 2.07 & 0.112 & 0.27 & 0.896 & 0.20 & 0.938 & 0.28 & 0.886 \\
\hline Block (B) & 7 & 1.73 & 0.143 & 0.83 & 0.573 & 2.24 & 0.061 & 0.35 & 0.926 \\
\hline $\mathrm{B} \times \mathrm{D}$ & 7 & 1.85 & 0.117 & 2.60 & $\mathbf{0 . 0 3 3}$ & 1.04 & 0.425 & 0.40 & 0.891 \\
\hline $\mathrm{B} \times \mathrm{I}$ & 7 & 0.22 & 0.978 & 0.93 & 0.496 & 0.88 & 0.534 & 0.49 & 0.833 \\
\hline $\mathrm{B} \times \mathrm{DI}$ & 7 & 1.44 & 0.228 & 0.36 & 0.920 & 0.63 & 0.731 & 0.85 & 0.558 \\
\hline $\mathrm{B} \times \mathrm{SQ}(\mathrm{I})$ & 28 & 0.82 & 0.685 & 0.90 & 0.608 & 1.09 & 0.438 & 1.53 & 0.882 \\
\hline Residual & 16 & & & & & & & & \\
\hline
\end{tabular}

Disturbance effects

Disturbance was without significant effect on evenness and species richness at both sampling events. Such comparable levels of diversity in strongly disturbed and undisturbed communities have also been predicted by the 'Intermediate Disturbance Hypothesis' (IDH) (Connell 1978; Kondoh 2001). Under harsh environmental conditions, communities are kept at an early successional stage with low diversity due to a constant removal of species, while competitive exclusion of inferior competitors reduces diversity in the absence of disturbance (e.g. Valdivia et al. 2005). In the present study, however, species richness increased monotonically and consistently in undisturbed assemblages, suggesting that competitive exclusion did not occur. At least two explanations seem feasible. First, early colonizers such as diatoms and filamentous species of macroalgae may have facilitated settlement of species throughout the study period. Such facilitation effects (sensu Connell and Slatyer 1977) of filamentous structures for the settlement of spores and larvae has been reported previously (Pulfrich 1996; Molis et al. 2003). Second, superior competitors were absent from the assemblage. This is corroborated by the consistently high levels of evenness during the study period, indicating a lack of dominant species. Two species, the blue mussel (M. edulis) and the sea squirt $C$. intestinalis are known to be strong competitors in a type of assemblage comparable to the one tested in the present study (Harms and Anger 1983; Dürr and Wahl 2004). However, mussels recruited in low numbers and, in contrast to earlier studies (Anger 1977), were unable to dominate the assemblages. Given the climate change related decline in mussel stocks at other sites in the region (Beukema and Dekker 2005, 2007), the role of mussels in structuring hard-bottom communities around Helgoland may continue to mitigate in the future. The second potential superior competitor, $C$. intestinalis, was unable to dominate the substratum during the 
study period and even vanished during the winter season. This suggests that the lack of competitive exclusion in undisturbed assemblages resulted from a reset of the succession during winter months rather than from the short duration of the study. Therefore, disturbance may not have long lasting effects on the diversity of hard-bottom assemblages that show strong seasonal recruitment patterns and transient appearance of superior competitors, like in the present study.

Surprisingly, species richness also increased monotonically during succession in disturbed assemblages despite the relatively high intensity of disturbance. Similar patterns were reported from other studies (reviewed in Mackey and Currie 2001). For instance, Lenz et al. (2004) explained higher levels of diversity under harsh than under moderate disturbance conditions by the development of an alternative community structure. However, this seems unlikely to apply to at our study site because significant differences in on species composition between disturbed and undisturbed assemblages were not recorded at the end of the study period.

\section{Effects of different disturbance regimes}

In our study, irregular disturbance regimes caused significantly higher biomass accrual, total cover, and $C$. intestinalis cover than a regular regime. This pattern may be due to differences in the rate at which open space became available for colonizers under the regular and the irregular disturbance regimes. In contrast to the regular disturbance regime, relatively larger patches of cleared or recently cleared substratum were opened in irregular disturbance regimes, due to clumping of disturbance events. Larger, contiguous patches are microhabitats that differ from smaller patches (Keough 1984) and could thereby affect recruitment in several ways. First, neighborhood effectsdetrimental effects of sweeping algal fronds on larval settlement and early recruitment have been reported to decrease when patch size increases (Jenkins et al. 1999). Second, trophic interactions-less predation pressure on recruits due to an increased visibility of meso-consumers to their predators in larger patches. Third, altered margin to area ratio-recruitment of macrobenthic species to smaller patches is more controlled by margin effects than recruitment to larger patches (Osman 1977). Fourth, sampling effect-the relative importance of propagule-mediated recruitment increases with patch size (Connell and Keough 1985) and chances rise that species with new traits, e.g. fast biomass accrual, enter the community. This assumes a disproportionately higher recruitment success of species in larger compared to smaller patches. However, as we did not observe differential recruitment success between regularly and irregularly disturbed assemblages this possibility seems unlikely.
The positive effects of irregular disturbance on biomass, total cover, and $C$. intestinalis cover were small compared to the detrimental effects of disturbance per se. This suggests that the irregularity of disturbance events was of very low importance under our experimental conditions. Although the effect size of irregular disturbance patterns was small, it counterbalanced to some degree the effects of detrimental disturbance per se, corroborating the findings of Benedetti-Cecchi et al. (2006) that high temporal variance may mitigate ecological impacts of climate changes. Possibly, the high intensity of the applied disturbance regime was responsible for the small effect size and repeating the experiments with lower mean intensity might have produced stronger effects by irregular disturbance regimes. The few studies that have tested for interactive effects of intensity and irregularity of disturbance on species richness, do suggest that the effects of irregular disturbance patterns can depend on the level of disturbance intensity (Bertocci et al. 2005; Benedetti-Cecchi et al. 2006). Yet, present evidence gives contrasting results about the direction of this interaction. For instance, mean intensity of aerial exposure either magnified or dampened the effects of temporal variability of aerial exposure in a species-specific manner (Bertocci et al. 2007).

In conclusion, the present study indicates that the effects of temporal variation in disturbance events were drastically lower in magnitude and of opposite direction than disturbance effects per se. This contrasts some of the recent findings from Mediterranean shores, suggesting that the effects of temporal variation in predictor variables are likely to be dependent on system-immanent characteristics and the type of factors under investigation. Using advanced experimental designs with variable factor regimes may in some but not all systems help to improve the assessment of generally important topics on climate change and the testing of models in ecology.

Acknowledgments We are grateful for the help of the R. V. Aade crew in setting up the experiment. Assistance during field work of C. Funk, K. Zacher, and the research divers. C. Wanke and S. Brandt are greatly acknowledged. We thank L. Benedetti-Cecchi for assistance in designing and analyzing the study. Earlier drafts of the manuscript benefited from discussions with other GAME students, in particular M. Cifuentes.

\section{References}

Anger K (1977) Development of a subtidal epifaunal community at the island of Helgoland. Helgol Meeresunters 31:457-470

Benedetti-Cecchi L (2003) The importance of the variance around the mean effect size of ecological processes. Ecology 84:23352346

Benedetti-Cecchi L, Vaselli S, Maggi E, Bertocci I (2005) Interactive effects of spatial variance and mean intensity of grazing on algal cover in rock pools. Ecology 86:2212-2222 
Benedetti-Cecchi L, Bertocci I, Vaselli S, Maggi E (2006) Temporal variance reverses the impact of high mean intensity of stress in climate change experiments. Ecology 87:2489-2499

Bertocci I, Maggi E, Vaselli S, Benedetti-Cecchi L (2005) Contrasting effects of mean intensity and temporal variation of disturbance on a rocky seashore. Ecology 86:2061-2067

Bertocci I, Vaselli S, Maggi E, Benedetti-Cecchi L (2007) Changes in temporal variance of rocky shore organism abundances in response to manipulation of mean intensity and temporal variability of aerial exposure. Mar Ecol Prog Ser 338:11-20

Beukema JJ, Dekker R (2005) Decline of recruitment success in cockles and other bivalves in the Wadden Sea: possible role of climate change, predation on postlarvae and fisheries. Mar Ecol Prog Ser 287:149-167

Beukema JJ, Dekker R (2007) Variability in annual recruitment success as a determinant of long-term and large-scale variation in annual production of intertidal Wadden Sea mussels (Mytilus edulis). Helgoland Mar Res 61:71-86

Connell JH, Slatyer RO (1977) Mechanisms of succession in natural communities and their role in community stability and organisation. Am Nat 111:1119-1144

Connell JH (1978) Diversity in tropical rain forests and coral reefs. Science 199:1302-1310

Connell JH, Keough MJ (1985) Disturbance and patch dynamics of subtidal marine animals on hard substrata. In: Pickett STA, White PS (eds) The ecology of natural disturbance and patch dynamics. Academic Press, Orlando, pp 125-151

Danard MB, Dube SK, Gonnert G, Munroe A, Murty TS, Chittibabu P, Rao AD, Sinha PC (2004) Storm surges from extra-tropical cyclones. Nat Hazards 32:177-190

de Kluijver MJ (1991) Sublittoral hard substrate communities off Helgoland. Helgol Meeresunters 45:317-344

Dürr S, Wahl M (2004) Isolated and combined impacts of blue mussels (Mytilus edulis) and barnacles (Balanus improvisus) on structure and diversity of a fouling community. J Exp Mar Biol Ecol 306:181-195

Grime PJ (1977) Evidence for the existence of three primary strategies in plants and its relevance to ecological and evolutionary theory. Am Nat 111:1169-1194

Harms J, Anger K (1983) Seasonal, annual, and spatial variation in the development of hard bottom communities. Helgol Meeresunters 36:137-150

Hooper DU, Chapin FS, Ewel JJ, Hector A, Inchausti P, Lavorel S, Lawton JH, Lodge DM, Loreau M, Naeem S, Schmid B, Setala H, Symstad AJ, Vandermeer J, Wardle DA (2005) Effects of biodiversity on ecosystem functioning: a consensus of current knowledge. Ecol Monogr 75:3-35

Hughes JB, Daily GC, Ehrlich PR (1997) Population diversity: its extent and extinction. Science 278:689-692

Jara VC, Miyamoto JHS, da Gama BAP, Molis M, Wahl M, Pereira RC (2006) Limited evidence of interactive disturbance and nutrient effects on the diversity of macrobenthic assemblages. Mar Ecol Prog Ser 308:37-48
Jenkins SR, Norton TA, Hawkins SJ (1999) Settlement and post-settlement interactions between Semibalanus balanoides (L.) (Crustacea: Cirripedia) and three species of fucoid canopy algae. J Exp Mar Biol Ecol 236:49-67

Keough MJ (1984) Effects of patch size on the abundance of sessile marine invertebrates. Ecology 65:423-437

Kjerfve B, Michener WK, Gardner LR (1994) Impacts of climate change in estuary and delta environments. University of South Carolina, Columbia

Kondoh M (2001) Unifying the relationships of species richness to productivity and disturbance. P R Soc Lond B Biol 268:269-271

Lenz M, Molis M, Wahl M (2004) Testing the intermediate disturbance hypothesis: response of fouling communities to various levels of emersion intensity. Mar Ecol Prog Ser 278:53-65

Loreau M (2000) Biodiversity and ecosystem functioning: recent theoretical advances. Oikos 91:3-17

Mackey RL, Currie DJ (2001) The diversity-disturbance relationship: is it generally strong and peaked? Ecology 82:3479-3492

Menge BA, Sutherland JP (1987) Community regulation: variation in disturbance, competition, and predation in relation to environmental stress and recruitment. Am Nat 130:730-757

Molis M, Lenz M, Wahl M (2003) Radiation effects along a UV-B gradient on species composition and diversity of a shallow-water macrobenthic community in the western Baltic. Mar Ecol Prog Ser 263:113-125

Morin PJ, McGrady-Steed J (2004) Biodiversity and ecosystem functioning in aquatic microbial systems: a new analysis of temporal variation and species richness-predictability relations. Oikos 104:458-466

Navarrete SA (1996) Variable predation: effects of whelks on a midintertidal successional community. Ecol Monogr 66:301-321

Osman RW (1977) The establishment and development of a marine epifaunal community. Ecol Monogr 47:37-63

Pulfrich A (1996) Attachment and settlement of post-larval mussels (Mytilus edulis L.) in the Schleswig-Holstein Wadden Sea. J Sea Res 36:239-250

Shea K, Roxburgh SH, Rauschert ESJ (2004) Moving from pattern to process: coexistence mechanisms under intermediate disturbance regimes. Ecol Lett 7:491-508

Sommer U (2000) Benthic microalgal diversity enhanced by spatial heterogeneity of grazing. Oecologia 122:284-287

Sugden H, Panusch R, Lenz M, Wahl M, Thomason JC (2007) Temporal variability of disturbance: in this important for diversity and structure of marine fouling assemblages? Mar Ecol 28:1-9

Svensson JR, Lindegarth M, Siccha M, Lenz M, Molis M, Wahl M, Pavia H (2007) Maximum species richness at intermediate frequencies of disturbance: consistency among levels of productivity. Ecology 88:830-838

Valdivia N, Heidemann A, Thiel M, Molis M, Wahl M (2005) Effects of disturbance on the diversity of hard-bottom macrobenthic communities on the coast of Chile. Mar Ecol Prog Ser 299:45-54 